\title{
INCLUSÃO DE ESTUDANTES COM DEFICIÊNCIA INTELECTUAL: Uma revisão sistemática da literatura
}

Carla Beatris Valentini Ruthie Bonan Gomes Cláudia Alquati Bisol ${ }^{*}$

\section{INTRODUÇÃO}

O avanço das reflexões sobre a democratização escolar e a difusão das políticas de inclusão, que asseguram o direito dos sujeitos com necessidades especiais a receberem uma educação não segregada de qualidade, ocasionou um aumento considerável no número de matrículas dos alunos com deficiência intelectual em escolas comuns (BRASIL, 2008). A maior presença desses alunos nas salas comuns, porém, ocorre em um cenário de mudanças e ajustes nas próprias diretrizes políticas federais e numa realidade pautada por diversidade de condições nos municípios de nosso país. Nesse contexto, em se tratando da deficiência intelectual, vários são os desafios para o desenvolvimento dos processos de aprendizagem, autonomia e cidadania (SANTOS, 2012; VELTRONE, MENDES, 2011b; BEZERRA, ARAUJO, 2011a; PLETSCH, GLAT, 2012).

Um desses desafios diz respeito à heterogeneidade da experiência da deficiência intelectual. Uma característica importante dessa condição é a impossibilidade de traduzir, em uma única definição, as diferentes potencialidades e dificuldades apresentadas pelos sujeitos com deficiência intelectual. Essa heterogeneidade deve-se, entre outras questões, à diversidade dos fatores etiológicos, às características comportamentais e às necessidades educativas singulares. Além disso, é importante é considerar que a deficiência intelectual não é uma condição estática e permanente (Pletsch, 2014). O potencial de um sujeito para responder aos padrões esperados para a sua idade e grupo social não se deve exclusivamente a uma suposta capacidade intrínseca, mas sim a uma complexa interação entre o sujeito, suas experiências de aprendizagem e o suporte social.

\footnotetext{
${ }^{(*)}$ Carla Beatris Valentini. Doutora em Informática na Educação. Professora do curso de Pedagogia e do Programa de Pós-Graduação em Educação - Universidade de Caxias do Sul (UCS). E-mail: carlabeam@gmail.com.

Ruthie Bonan Gomes. Graduada em Psicologia. Mestranda do Programa de Pós-Graduação em Psicologia Universidade Federal de Santa Catarina (UFSC). E-mail: tutti.gomes@gmail.com.

Cláudia Alquati Bisol. Doutora em Psicologia. Professora do curso de Psicologia e do Programa de Pós-Graduação em Educação - Universidade de Caxias do Sul (UCS).E-mail: claubisol@gmail.com.
} 
Outro desafio está relacionado ao conceito de deficiência intelectual. Diferentes paradigmas ou modelos conceituais se apresentaram ao longo do tempo e suas implicações no ambiente escolar são significativas. Por exemplo, encontra-se ainda presente nas escolas concepções de deficiência pautadas no déficit. No caso da deficiência intelectual, o quociente de inteligência (QI), criado no início do século XX, se tornou expressão numérica onipresente, de caráter incurável e inalterável (BELO et al., 2008). Mudanças de nomenclatura, por sua vez, exemplificam as tentativas de se modificar o olhar sobre a deficiência intelectual. A Associação Americana de Retardo Mental (AAMR) passou a denominar-se Associação Americana para as Dificuldades Intelectuais e Desenvolvimentais (AAIDD). Essa mudança de nomenclatura reflete mudanças de concepção. Nosso país tem adotado a terminologia, definição e recomendações da AAIDD (VELTRONE; MENDES, 2013).

O campo de estudos sobre a deficiência também procurou questionar olhares redutores, individualizantes e deterministas em relação à deficiência. A deficiência intelectual pode ser olhada como uma condição imutável, fixa, que determina taxativamente o destino de um sujeito, ou pode ser problematizada no entrelaçamento dialético entre as condições ambientais, histórico-culturais e as condições subjetivas da pessoa que um dia recebeu o diagnóstico de deficiência intelectual (DIAS; OLIVEIRA, 2013).

A retomada das contribuições de Vigotski tem apoiado significativamente para essa mudança de paradigma. Vigotski, em texto cuja escrita é datada aproximadamente entre 1924 e 1931 (VIGOTSKI, 2011), tecia uma distinção entre o que ele chamou na época de olhar tradicional e olhar contemporâneo sobre a educação da criança anormal (termo que ele utiliza nesse escrito). $\mathrm{O}$ olhar tradicional, segundo ele, é aquele que parte da ideia de que o "defeito" (leia-se, hoje, “deficiência”), limita o desenvolvimento da criança. A ênfase desse olhar tradicional está na falha, na perda de uma função. Já o olhar contemporâneo que Vigotski está propondo nesse texto, enfatiza a possibilidade do desenvolvimento de caminhos alternativos:

Para substituir essa compreensão, surge outra, que examina a dinâmica do desenvolvimento da criança com deficiência partindo da posição fundamental de que o defeito exerce uma dupla influência em seu desenvolvimento. Por um lado, ele é uma deficiência e atua diretamente como tal, produzindo falhas, obstáculos, dificuldades na adaptação da criança. Por outro lado, exatamente porque o defeito produz obstáculos e dificuldades no desenvolvimento e rompe o equilíbrio normal, ele serve de estímulo ao desenvolvimento de caminhos alternativos de adaptação, indiretos, os quais substituem ou superpõem funções que buscam compensar a deficiência e conduzir todo o sistema de equilíbrio rompido a uma nova ordem (VIGOTSKI, 2011. p. 869). 
Encontram-se ainda hoje, nas escolas, olhares tradicionais e métodos de ensino que não auxiliam professores e estudantes a ultrapassar as barreiras da falha, da perda, do limite. Esses olhares e métodos tendem a potencializar as dificuldades, o fracasso e as resistências à inclusão do estudante com deficiência intelectual nas classes comuns. Felizmente, encontram-se também iniciativas e experiências facilitadoras, que têm propiciado caminhos possíveis para a prática docente. Esse artigo se propõe a olhar para essas experiências, ao situar o objetivo da presente revisão sistemática de literatura na identificação de aspectos facilitadores para a inclusão de estudantes com deficiência intelectual em escolas comuns.

\section{Método}

Esta pesquisa constitui-se em um estudo qualitativo, exploratório descritivo, realizado através do processo de revisão sistemática de literatura. Esse método propõe o agrupamento, síntese e integração das evidências científicas geradas por resultados de pesquisas empíricas (MEDRADO, GOMES, NUNES SOBRINHO, 2014).

A coleta de dados compreendeu a busca de artigos indexados nas bases de dados do Portal de Periódicos CAPES e duas revistas especializadas (Revista Brasileira de Educação Especial e Revista Educação Especial - UFSM). A inclusão dessas duas revistas especializadas foi realizada porque identificou-se que alguns artigos desses periódicos de publicação mais recente não estavam ainda indexados no sistema de busca do Portal Capes. Os descritores utilizados foram: deficiência mental, deficiência intelectual, Síndrome de Down e inclusão escolar. A busca foi realizada entre os anos de 2008 e 2015. Esta delimitação de tempo levou em consideração os possíveis impactos que a Política Nacional de Educação Especial na Perspectiva da Educação Inclusiva (BRASIL, 2008) podem ter trazido para essa discussão.

Utilizou-se a análise de conteúdo proposta por Bardin (2011), constituída em três etapas. Na pré-análise realizou-se leitura flutuante para escolha dos artigos, sendo que dos 115 artigos identificados na busca inicial, 43 foram selecionados. Foram excluídos os artigos não relacionados à inclusão em escolas comuns. A etapa seguinte da análise consistiu na exploração do material, definiu-se pela utilização de categorias apriorísticas, seguindo estudo realizado por Bisol, Sangherlin e Valentini (2013) sobre o estado da arte das publicações científicas das áreas da Educação e Psicologia. As subcategorias foram definidas a posteriori, a partir da leitura dos artigos na íntegra. A seguir foi realizado o tratamento dos resultados (inferência e interpretação). Nesta fase buscou-se a condensação e destaque das informações para análise. 
O quadro abaixo apresenta as categorias e suas subcategorias, que serão presentadas e discutidas na sequencia.

Quadro 1: Quadro das categorias e subcategorias temáticas

\begin{tabular}{ll}
\hline Categorias & Subcategorias \\
\hline \multirow{3}{*}{ Escola } & Aceitação da diversidade \\
\cline { 2 - 2 } & $\begin{array}{l}\text { Trabalho integrado e multidisciplinar } \\
\text { Planejamento, adequações curriculares e avaliação }\end{array}$ \\
\cline { 2 - 2 } & $\begin{array}{l}\text { Recursos humanos e didático-pedagógicos } \\
\text { Atendimento Educacional Especializado (AEE) }\end{array}$ \\
\hline Professores & Prática pedagógica \\
\cline { 2 - 2 } & Crenças e atitudes \\
\hline Governo & Formação \\
\hline Família & Investimentos \\
\hline Colegas & Participação dos pais \\
\hline
\end{tabular}

\section{RESULTADO E DISCUSSÃO}

Optamos, neste trabalho, por discutir em detalhes as duas primeiras categorias por trazerem muitos dados com contribuições mais específicas. Para as três últimas categorias não encontramos muitos dados, tampouco especificidades relacionadas à Deficiência Intelectual.

\section{Categoria 1: Escola}

Esta primeira categoria refere-se aos aspectos facilitadores do processo inclusivo vinculados diretamente à escola. O Quadro 2 foi organizado apresentando as quatro subcategorias. Os indicadores representam as afirmações e conclusões identificadas nos textos e foram agrupados considerando as propostas/ideias afins.

\section{Quadro 2: Quadro dos indicadores emergentes em cada subcategoria temática da categoria Escola}

\begin{tabular}{|c|c|c|}
\hline & Subcategorias & Indicadores \\
\hline \multirow[t]{2}{*}{ 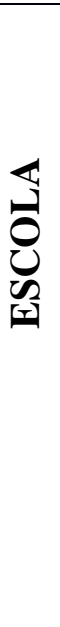 } & $\begin{array}{l}\text { Aceitação da } \\
\text { diversidade }\end{array}$ & $\begin{array}{l}\text { - Escuta/reconhecimento dos alunos com DI (CARLINO, 2010; GOMES; GONZÁLES-REY, } \\
\text { - Mo08). } \\
\text { - Mobilização para perceber/acolher o outro (OLIVEIRA; MARTINS, 2011). Cultura de } \\
\text { para o processo de inclusão (FANTACINI; DIAS, 2015). } \\
\text { - Trabalho com a necessidade de cada aluno (VELTRONE; MENDES, 2009; SANTOS, 2012; } \\
\text { LUIZ et al., 2012). Constituição dos espaços escolares e de estratégias metodológicas de ensino } \\
\text { direcionadas a indivíduos singulares e subjetivamente constituídos (CUNHA; ROSSATO, 2015). } \\
\text { - Propiciar espaços de debates com a comunidade sobre o processo de inclusão, garantindo que } \\
\text { esses estudantes sejam ouvidos em suas expectativas, desejos, frustrações (CUNHA; ROSSATO, } \\
\text { 2015). }\end{array}$ \\
\hline & Trabalho integrado & $\begin{array}{l}\text { - Integração entre escola e família (RODRIGUES et al., 2014; SMEHA; OLIVEIRA, 2014; } \\
\text { FERRAZ et al., 2010; DUARTE; MUNHÓZ, 2008; LUIZ et al., 2012; LUIZ; NASCIMENTO, } \\
\text { 2012; SILVA; BELO; DRUMOND, 2011). Escuta e estabelecimento de parceria com as mães } \\
\text { (SMEHA; OLIVEIRA, 2014; FERRAZ et al., 2010). Intervenções em habilidades sociais por } \\
\text { parte da escola junto aos pais (RODRIGUES et al., 2014). Horário fixo para contato com a } \\
\text { família (FERRAZ; ARAUJO; CARREIRO, 2010). }\end{array}$ \\
\hline
\end{tabular}




\begin{tabular}{|c|c|}
\hline & $\begin{array}{l}\text { - Integração entre professores da escola comum e professores da escola especial (LOPES; } \\
\text { MARQUEZINE, 2012; ARAUJO; ALMEIDA, 2014; BEZERRA; ARAUJO, 2011b; } \\
\text { VELTRONE; MENDES, 2009). } \\
\text { - Ação colaborativa e co-responsabilização entre os professores da sala comum com professor } \\
\text { - especialista do AEE (FANTACINI; DIAS, 2015; BRAUN; NUNES, 2015). } \\
\text { - Integração entre escola/professores de sala comum e professores auxiliares ou monitores } \\
\text { (STELMACHUK; MAZZOTA, 2012). } \\
\text { - Integração entre universidade e escola (ARAUJO; ALMEIDA, 2014). } \\
\text { - Articulação do trabalho de forma integrada com família, escola e serviços da saúde } \\
\text { (DELPRETTO; SANTOS, 2013). } \\
\text { - Integração com toda a escola (VELTRONE; MENDES, 2011a). } \\
\text { - Papel positivo da coordenação pedagógica no processo de encaminhamento e diálogo entre } \\
\text { equipe gestora e professores sobre os encaminhamentos para o AEE. Participação da gestão no } \\
\text { processo de inclusão (STELMACHUK; HAYASHI, 2015). } \\
\text { - Avaliação realizada por equipe multidisciplinar com a participação do professor especializado. } \\
\text { (STELMACHUK Y HAYASHI, 2015). Matrícula do aluno no serviço de apoio mediante } \\
\text { Relatório de Avaliação Psicoeducacional (LOPES; MARQUEZINE, 2012; DELPRETTO; } \\
\text { SANTOS, 2013). } \\
\text { - Construção de redes de apoio e/ou redes de colaboração entre as diferentes áreas de } \\
\text { conhecimento como suporte ao trabalho pedagógico desenvolvido pela escolar regular } \\
\text { (RODRIGUES; CAMPOS; ALMEIDA, 2015). } \\
\text { - Parceria entre professores (artes, educação física, informática, etc..) e profissionais que atendem } \\
\text { o aluno (FANTACINI; DIAS, 2015). Entrosamento entre professores das disciplinas por meio de } \\
\text { discussões a respeito das estratégias de ensino (CUNHA; ROSSATO, 2015). } \\
\text { - Estímulo ao contato de todos os profissionais da escola com os alunos com DI (LUIZ et al., } \\
\text { 2012). } \\
\text { - Cuidado para que os serviços e recursos do atendimento estejam garantindo a participação do } \\
\text { aluno nas atividades escolares (FANTACINI; Dias, 2015). } \\
\text { - Trabalho realizado em três eixos: Eixo } 1 \text { - Atendimento individual; Eixo } 2 \text { - Trabalho } \\
\text { colaborativo com professores da classe comum; Eixo } 3 \text { - Trabalho colaborativo com a família } \\
\text { (LOPES; MARQUEZINE, 2012). }\end{array}$ \\
\hline $\begin{array}{l}\text { Planejamento e } \\
\text { adequações curriculares }\end{array}$ & $\begin{array}{l}\text { - Adequação dos ambientes para atividades motoras (CRUZ; LEMISHKA, 2010). } \\
\text { - Organização do ambiente escolar e de novas situações de ensino e aprendizagem (TEIXEIRA; } \\
\text { KUBO, 2008; VELTRONE; MENDES, 2009). Organizar a dinâmica escolar para que o } \\
\text { estudante participe ativamente de todas as atividades produzindo conhecimento, posicionando-se } \\
\text { como um sujeito que aprende (CUNHA; ROSSATO, 2015). } \\
\text { - Planejamento de apoios necessários dos serviços especializados (VELTRONE; MENDES, 2009). } \\
\text { - Busca de instrumentos e situações adequadas de avaliação (SILVA; BELO; DRUMOND, 2011). } \\
\text { Valorização das capacidades individuais dos sujeitos no processo avaliativo (PLETSCH; GLAT, } \\
\text { 2012; LIMA; MENDES, 2011). } \\
\text { - Adequações pautadas nas necessidades dos alunos (FERRAZ et al., 2010; LUIZ et al. 2012; } \\
\text { OLIVEIRA; MARTINS, 2011; LOPES; MARQUEZINE, 2012). Estabelecimento de estratégias } \\
\text { para que os sujeitos aprendam, mesmo que em ritmos e estilos diferenciados (CUNHA; } \\
\text { ROSSATO, 2015). } \\
\text { - Inserção da educação especial no PPP da escola (DALPRETTO; SANTOS, 2013). } \\
\text { - Reformulação das ações e estabelecer novas estratégias e recursos, bem como retomada do plano } \\
\text { de AEE para o aluno, conforme necessidade identificada no acompanhamento e avaliação pelos } \\
\text { professores. (FANTACINI; DIAS, 2015). Realização do Plano de Desenvolvimento Educacional } \\
\text { Individual (PDEI) (SILVA; BELO; DRUMOND, 2011; SANTOS, 2012; PLETSCH; GLAT, } \\
\text { 2012). } \\
\text { - Entendimento aprofundado sobre as adaptações curriculares a partir do que os documentos } \\
\text { apontam, para que a sua implantação se torne mais efetiva, visto ser um processo } \\
\text { em construção (FANTACINI; DIAS, 2015). } \\
\text { - Matrícula no mesmo nível de ensino da escola anterior ou idade (VELTRONE; MENDES, } \\
\text { 2009). } \\
\text { - Cuidado referente à quantidade de alunos por sala (STELMACHUK; MAZZOTA, 2012). }\end{array}$ \\
\hline $\begin{array}{l}\text { Recursos didático- } \\
\text { pedagógicos }\end{array}$ & $\begin{array}{l}\text { - Utilização de recursos pedagógicos como programas, jogos e softwares (HEIN et al., 2010; } \\
\text { BEZERRA; ARAUJO, 2011b); } \\
\text { - Utilização do sistema PECS (evidenciou aumento das iniciações comunicativas, do vocabulário e } \\
\text { independência para se comunicar com diferentes pessoas) (RODRIGUES; CAMPOS; } \\
\text { ALMEIDA, 2015) }\end{array}$ \\
\hline
\end{tabular}




\begin{tabular}{|l|l|l|}
\hline & $\begin{array}{l}\text { que o estudante busca dicas para a resolução de sua tarefa (BRAUN; NUNES, 2015) } \\
\text { - Atividades lúdicas (propiciaram desenvolvimento individual e coletivo) (ANUNCIAÇÃO; } \\
\text { COSTA; DENARI, 2015). } \\
\text { - Divulgação de práticas significativas que são desenvolvidas na escola para que sirvam como } \\
\text { parâmetros em outros espaços sociais, mostrando que é possível realizar ações pedagógicas que } \\
\text { oportunizem a aprendizagem dos sujeitos (CUNHA; ROSSATO, 2015). }\end{array}$ \\
\hline
\end{tabular}

Pensar a escola diante da Política Nacional para a Educação Inclusiva implica também pensar o papel da escola brasileira no contexto atual, cujo foco se coloca na universalização da educação básica. Embora não seja esse o foco do texto, destaca-se que pensar o papel da escola no contexto da educação inclusiva não pode se dar desconsiderando uma perspectiva maior, as políticas públicas e sua preocupação ou não com a finalidade da escola e o contexto social heterogêneo no qual as escolas brasileiras se situam. A escola vive as contradições que se colocam entre as exigências, desafios e os parcos investimentos tanto em termos financeiros, como em formação, pesquisa e inovações pedagógicas (CHARLOT, 2007).

As escolas brasileiras se constituem em contextos heterogêneos, nos mais diversos aspectos, o que desacomoda e exige movimentos. Trata-se desafio que não se vinculam somente com a questão das deficiências ou da educação inclusiva. Cabe à escola se questionar sobre como lida com as diferenças em geral e não somente com as deficiências em particular.

Embora essa questão da diversidade tenha acompanhado historicamente a educação, parece que as práticas ainda precisam incorporar o discurso da diferença e da diversidade, pois onze artigos apontam para essa questão evidenciando a necessidade de considerar essa perspectiva para uma escola que se considere inclusiva. A subcategoria aceitação da diversidade compõe-se dos aspectos relativos ao reconhecimento dos potenciais e características individuais dos alunos por parte da escola, acolhimento da diferença, bem como da organização escolar necessária para atender as necessidades e particularidades dos estudantes. Identificou-se que a aceitação da diversidade associa-se a necessidade de escuta por parte da escola ao aluno com DI sobre as suas efetivas necessidades de participação educacional e social (CARLINO, 2010). Luiz et al. (2012) enfatizam a necessidade de atitudes positivas em relação às crianças com DI, respeitando suas diferenças e seus limites. Para tanto, faz-se necessária uma mudança de paradigma, numa educação voltada para a cidadania e pela ausência de preconceitos. Cunha e Rossato (2015) discutem a necessidade de refletir sobre a singularidade do estudante com DI frente ao modelo homogeneizado que a escola concebe os processos de aprendizagem. O não reconhecimento e abertura para a expressão do estudante reforça a deficiência e produz a invisibilidade desse sujeito. Dias e Fantacini (2015, p. 66) destacam que "desenvolver a cultura de acolhimento é um dos primeiros passos para a aceitação da 
diversidade". As contribuições dessa categoria provocam a incluir a perspectiva de acolhimento, da diversidade e da diferença como pressupostos fundamentais das formações e práticas inclusivas.

A subcategoria trabalho integrado concentrou a maior quantidade de extratos, o que reflete tanto a importância da atuação integrada entre os professores, demais profissionais e famílias, como também a fragilidade de operacionalizar essa articulação nas escolas brasileiras. Esta subcategoria compõe-se dos aspectos relativos ao trabalho realizado na escola e pela escola com todos envolvidos no processo de escolarização do estudante com DI: professores do ensino comum, professores do ensino especial, professores do Atendimento Educacional Especializado (AEE), profissionais da saúde, família e professores/pesquisadores.

Os indicadores dessa categoria apontam para várias possibilidades de parcerias, evidenciando a necessidade da educação inclusiva não ser uma ação exclusiva de alguns professores ou profissionais, mas da responsabilização de todos os agentes, como cúmplices nesse processo. Destaca-se entre os aspectos facilitadores o envolvimento e a interação com a família. Nesse sentido Beyer (2010) aponta para a importância da abordagem ativa no movimento de inclusão escolar. Nessa abordagem pais e educadores acreditam e investem nas potencialidades da criança. Mas esse movimento precisa de suporte aos pais buscando suavizar as dificuldades na relação com a criança (CAMPOS, 2002). No artigo de Glat e Pletsch (2004) as autoras destacam a importância de deslocar as investigações do foco nas dificuldades e carências para alternativas de educação e estratégias de orientação familiar, com foco preferencial nas ações interdisciplinares.

Um dos aspectos identificados como facilitador no processo inclusivo do aluno com DI é o Plano de Desenvolvimento Individual ou Plano Educacional Individualizado. Este plano constituise como um instrumento importante para que se possam desenvolver atividades planejadas conforme as necessidades de cada aluno e para que a escola e a família possam acompanhar o seu desenvolvimento. Contudo, para que seja aplicado de maneira efetiva, deve ser elaborado por todos os envolvidos (SILVA, BELO E DRUMOND, 2011).

A subcategoria planejamento e adequações curriculares diz respeito a todas as ações, em nível institucional, que envolvem planejamento e currículo, que a escola deve atentar para efetivar a inclusão do aluno com DI. Essas ações são relevantes, fazem interface com o AEE e vinculam-se à coordenação pedagógica, à gestão e ao trabalho docente.

Para Veltrone e Mendes (2009), um planejamento que influencie práticas inclusivas bemsucedidas passa, necessariamente, pela organização de novas situações de ensino aprendizagem que 
envolvem: a diferenciação do ensino, a flexibilização das metodologias, adaptações curriculares e o trabalho cooperativo. As adaptações curriculares aparecem nos artigos associadas à qualidade de ensino e são apontadas como essenciais para facilitar o processo inclusivo do aluno com deficiência intelectual, mas requerem cuidadoso acompanhamento de educadores, pais e sociedade (FERRAZ, ARAÚJO E CARREIRO, 2010). Santos (2012) afirma que quando são realizadas definições claras referentes aos quadros específicos das dificuldades, estratégias de ação especializadas podem ser aplicadas, potencializando os processos de aprendizagem. Para Luiz et al. (2012) é desejável que a escola regular propicie as adequações em seus recursos e estrutura para receber a criança com DI, e que esta não seja colocada em prova, no intuito de verificar se ela se adapta ou não à proposta curricular do ensino regular.

Contudo, para isso que isso ocorra, é importante considerar as diretrizes já existentes capazes de orientar o trabalho pedagógico inclusivo. Estas orientações, por sua vez, devem ser compartilhadas e pensadas com toda a equipe da escola, para que se possa garantir uma intervenção consciente e comprometida com a formação dos alunos com deficiência intelectual. As transformações nos contextos evidenciam a necessidade de se repensar os currículos. Diante disso, se faz necessária a discussão sobre as diretrizes curriculares definidas no Projeto Político Pedagógico, bem como o encaminhamento de orientações mais claras e a implementação de ações efetivas que contemplem também os alunos com deficiência intelectual, entre outros que também apresentam necessidades educacionais especiais (OLIVEIRA E MARTINS, 2011).

A valorização das capacidades individuais é apontada pelos autores como uma oportunidade de superar o processo avaliativo focado nas limitações dos sujeitos (SILVA; BELO; DRUMOND, 2011; PLETSCH; GLAT, 2012; LIMA; MENDES, 2011). Lima e Mendes (2011) afirmam que é preciso que as práticas educativas e a forma de avaliar considerem a pessoa em sua especificidade, possibilitando o acompanhamento acadêmico do educando ao longo de sua escolarização e a descrição e análise de seu sucesso ou insucesso. Além disso, apontam para necessidade de que as práticas educacionais e avaliativas superem as visões que comparam os sujeitos com deficiência aos padrões da forma e ritmo de aprendizagem dos alunos sem deficiência. Nas concepções de Silva, Belo e Drumond (2011) cabe ao professor buscar os instrumentos e as situações adequadas de avaliação, valorizando sempre a oralidade e as experiências diárias, levando-se mais em consideração os aspectos qualitativos em relação aos quantitativos. 
A subcategoria recursos didático-pedagógicos engloba artigos que apresentam aspectos facilitadores referentes aos recursos, tanto digitais como jogos e materiais adaptados, que facilitam o processo de inclusão dos alunos com DI.

Diversos estudos se dedicam a apresentar e discutir recursos e ferramentas que podem potencializar o processo de aprendizagem e a mediação docente. Albuquerque, Mori e Lacanallo (2009) sugerem o uso de jogos, visto que nesses torna-se presente o desafio, a socialização, a mediação e a discussão de estratégias e raciocínios, auxiliando na formação de conceitos, na resolução de situações-problemas e exigindo que se faça o uso da linguagem para que o aluno consiga expressar de maneira clara suas ideias e intenções. Contudo, o jogo deve ser mediado de forma a explorar a leitura, a escrita, a interpretação, a abstração, o raciocínio lógico, a atenção e a memória, oferecendo caminhos para que o sujeito parta do âmbito particular para o geral, considerando seus conhecimentos prévios. Anunciação, Costa e Denari (2015) apontam as possibilidades do brincar e do jogo no desenvolvimento cognitivo e motor, destacando a necessidade da organização e proposição de atividades que busquem apoiar as aprendizagens que estejam em foco pelo professor. Braun e Nunes (2015) destacam como as experiências concretas e anteriores podem apoiar o desenvolvimento de conceitos abstratos, no entanto, não basta a utilização de recursos concretos, sendo fundamental considerar como é estruturado o pensamento do estudante com DI para apoiar seu processo de aprendizagem a partir de mediações adequadas.

Outros estudos evidenciaram o uso de tecnologias digitais. Por exemplo, o estudo de Hein et al. (2010) com o software Alfabetização Fônica Computadorizada mostrou que as crianças do grupo experimental desenvolveram habilidades de consciência fonológica e correspondências letrasom, o que, possivelmente, repercutiu em ganhos significativos na decodificação grafofonêmica. Esse mesmo software também é citado no estudo de Bezerra e Araújo (2011b), destacando a importância da utilização do recurso computacional focado nas particularidades e necessidades de cada aluno. Cechin, Costa e Dorneles (2013) sugerem diversas alternativas: o programa Numeracy Developmental Project é uma proposta de ensino de aritmética que utiliza o ensino direto, explícito e a prática contínua dos procedimentos e processos de contagem. Outro recurso, o Multisensory Approach, combina a visão, a audição e o tato com o ensino de técnicas de contagem para a resolução de problemas matemáticos. O Touch Math, por sua vez, integra atividades táteis ao ensino de habilidades matemáticas básicas e mostra resultados favoráveis na pontuação em testes de matemática em diversos países. Cunha e Rossato (2015) também evidenciam as possibilidades de significação do uso da língua escrita através de interações com mídias digitais como celular e rede 
social, mas da mesma forma que as autoras anteriores, apontam a importância da mediação articulada às especificidades de cada sujeito.

\section{Categoria 2: Professores}

Esta categoria compõe-se de aspectos relativos ao docente no que diz respeito à prática pedagógica, às crenças e atitudes e ao processo de formação. Sendo um dos papéis do professor criar condições para a aprendizagem dos estudantes, Libâneo (2004, p. 5) destaca que na mediação docente, "o professor se põe entre o aluno e o conhecimento para possibilitar as condições e os meios de aprendizagem, ou seja, as mediações cognitivas". Na relação professor e aluno, aspectos afetivos, cognitivos e sociais são movimentados por suas trocas, que se sustentadas pelo pressuposto das possibilidades de cada sujeito, podem abrir caminho em direção à aprendizagem e ao desenvolvimento.

O Quadro 3 foi organizado apresentando as três subcategorias e seus indicadores que foram agrupados considerando as propostas/ideias afins.

Quadro 3: Quadro dos indicadores emergentes em cada subcategoria temática da categoria Professores

\begin{tabular}{|c|c|c|}
\hline & Subcategorias & Indicadores \\
\hline 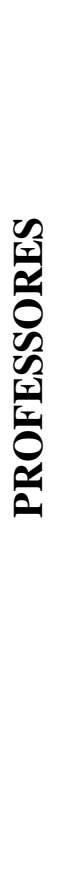 & Prática Pedagógica & $\begin{array}{l}\text { - Realização atendimentos diferenciais fora do horário de aula (TEIXEIRA; KUBO, 2008). } \\
\text { - Realização de atividades que promovam autonomia intelectual e social (SILVA; OLIVEIRA, } \\
\text { - Utilizaçãa de instrumentos pedagógicos voltados para memória visual associado com a auditiva } \\
\text { (FERREIRA et al., 2010). } \\
\text { - Desenvolvimento de conteúdos de forma diversificada nas aulas de educação física (CRUZ; } \\
\text { LEMISHKA, 2010). } \\
\text { - Foco em objetivos comuns entre professores e alunos (FERREIRA et al., 2010). } \\
\text { - Utilização do desenho infantil para favorecer emergência de processos psicológicas superiores } \\
\text { (BEZERRA; ARAÚJO, 2011a). } \\
\text { - Estímulo à atividade verbal (BEZERRA; ARAÚJO, 2011b). } \\
\text { - Formação de grupos de trabalho compostos por alunos com diferentes níveis de competência } \\
\text { (TOLEDO; VITALIANO, 2012). Utilização da "Tutoria de Colegas" (SANTOS; MENDES, } \\
\text { 2008). } \\
\text { - Atenção à mediação adequada nas atividades (SILVA; OLIVEIRA, 2010; PEDRO; CHACON, } \\
\text { 2013). Mediação do professor apoiando a estruturação do pensamento do estudante (BRAUN; } \\
\text { NUNES, 2015). } \\
\text { - Fortalecimento de habilidades sociais na interação entre colegas (TEIXEIRA; KUBO, 2008; } \\
\text { RODRIGUES et al., 2014; ESTEVES et al., 2013). Interação com o professor, tanto nas } \\
\text { interaç̃̃es não-acadêmicas quanto acadêmicas (GARGHETTI; NUERNBERG; MEDEIROS, } \\
\text { 2015). } \\
\text { - Diversificação das estratégias de ensino e realização de adaptações curriculares (SANTOS; } \\
\text { MARTINS, 2015). } \\
\text { - Organização de conceitos que partam de situações cotidianas (BRAUN; NUNES 2015). }\end{array}$ \\
\hline
\end{tabular}




\begin{tabular}{|c|c|}
\hline Crenças e atitudes & $\begin{array}{l}\text { - Valorização de aspectos subjetivos de cada sujeito considerando as trocas sociais (GOMES ; } \\
\text { GONZÁLES-REY, 2008). Valorização da individualidade/subjetividade dos alunos (SILVA; } \\
\text { BELO; DRIMOND, 2011; GOMES; GONZÁLES-REY, 2008; PLETSCH; GLAT, 2012; } \\
\text { BEZERRA; ARAUUO, 2011a). } \\
\text { - Reconhecimento da diversidade e heterogeneidade (SILVA; OLIVEIRA, 2010; FERREIRA et } \\
\text { al., 2010). Respeito ao ritmo de aprendizagem dos alunos (OLIVEIRA; MARTINS, 2011). } \\
\text { - Foco nas potencialidades, superando concepções orgânicas (TOLEDO; VITALIANO, 2012; } \\
\text { ESTEVES et al., 2013; ALBUQUERQUE et al., 2009). Reflexão para romper visões estáticas } \\
\text { e orgânicas (BEZERRA; ARAUJO, 2011a). } \\
\text { - Compreensão da dificuldade como fruto das interações sociais e pedagógicas estabelecidas em } \\
\text { sala de aula (PLETSCH; GLAT, 2012). } \\
\text { - Crença na possibilidade de aprendizagem do estudante com DI, compreendendo a } \\
\text { aprendizagem como um processo singular e percebendo o aluno como um ser com potencial } \\
\text { para a aprendizagem (SANTOS; MARTINS, 2015). Reconhecimento do potencial do aluno } \\
\text { (BEZERRA; ARAUJO, 2011b; CUNHA; ROSSATO, 2015). }\end{array}$ \\
\hline Formação & $\begin{array}{l}\text { - Disciplinas que tratem a diversidade na formação inicial (VELTRONE; MENDES, 2009). } \\
\text { - Conhecimento das concepções da deficiência (LOPES; MARQUEZINE, 2012). Compreensão } \\
\text { do funcionamento neurológico (FERREIRA et al., 2010). Domínio técnico (BEZERRA; } \\
\text { ARAUJO, 2011a). } \\
\text { - Desenvolvimento do currículo de formação docente orientado por categorias como cultura, } \\
\text { conhecimento, poder, ideologia, linguagem, história, discriminação (OLIVEIRA; MARTINS, } \\
\text { 2011). Revisão de currículos e conceitos dos cursos de formação de professores (PLETSCH; } \\
\text { GLAT, 2012). } \\
\text { - Informações a respeito da necessidade educacional especial do aluno e de seu processo de } \\
\text { ensino e aprendizagem (LOPES; MARQUEZINE, 2012). } \\
\text { - Motivação para atualizar conhecimentos (LUIZ et al., 2012). } \\
\text { - Desenvolvimento de pesquisa colaborativa para reflexão e união da prática com teoria } \\
\text { (TOLEDO; VITALIANO, 2012). } \\
\text { - Disponibilização de conhecimentos teórico-práticos e suporte aos profissionais da Educação } \\
\text { (PLETSCH; GLAT, 2012). } \\
\text { - Investigação das dificuldades enfrentadas no dia a dia das salas inclusivas (DALPRETTO; } \\
\text { SANTOS, 2013). }\end{array}$ \\
\hline
\end{tabular}

A subcategoria prática pedagógica pode ser compreendida a partir do que propõe Sacristán (2000), ou seja, é na prática pedagógica que os conteúdos curriculares ganham valor, sendo que nela estão inseridas ideias, valores e estratégias, ou seja, consiste em uma situação social de grande complexidade e fluidez, a qual prevê reflexão, iniciativa, diálogo, socialização e desenvolvimento. Na educação inclusiva, a prática pedagógica evidencia um grande desafio para os professores, pois implica também em presença, participação e aprendizagem exitosa de todos estudantes (ECHEITA; AINSCOW, 2010).

Nos artigos analisados encontramos diferentes aspectos facilitadores que, em sentido amplo, estão relacionados à prática pedagógica com foco no trabalho na atenção ao potencial individual, com propostas focadas e adaptadas às demandas individuais e que provoquem e favoreçam interações entre os colegas. Estudos apontam para a importância de o docente identificar as limitações existentes nas interações e relações entre os alunos com necessidades especiais e os que não apresentam tais necessidades, pois, a partir desta percepção, o docente poderá ser capaz de desenvolver práticas educativas e programas que promovam novas interações no grupo. Ao atentar para o potencial individual do estudante com DI o professor pode orientar o processo educativo 
identificando quais são as vias compensatórias, quais as funções psicológicas superiores que estão preservadas e quais que estão comprometidas.

Outro aspecto relativo à prática pedagógica que foi evidenciado diz respeito ao fortalecimento das habilidades sociais (TEIXEIRA; KUBO, 2008) e da interação entre colegas (FERRAZ; ARAUJO; CARREIRO, 2010). Os estudos apontam que cabe aos docentes identificar as limitações existentes nas interações e relações entre os alunos com necessidades especiais e os que não apresentam tais necessidades. A partir desta percepção o docente poderá desenvolver práticas educativas e programas que promovam novas interações no grupo e que promovam fortalecer os vínculos entre os estudantes (TEIXEIRA; KUBO, 2008; RODRIGUES; SANTOS; CARLINO, 2014). Teixeira e Kubo (2008) sugerem apresentar comportamentos cooperativos ao invés de competitivos aos alunos. Toledo e Vitaliano (2012) sugerem a formação de grupos de trabalho compostos por alunos com diferentes níveis de competência, para que os mais adiantados auxiliem como mediadores os demais.

Vários estudos destacam a questão da mediação na perspectiva histórico-cultural de Vigotski como uma condição favorecedora para a aprendizagem do estudante (SILVA; OLIVEIRA, 2010; PEDRO; CHACON, 2013; BRAUN; NUNES, 2015). O professor no papel de mediador pode atuar contribuindo para a estruturação do pensamento do estudante com DI, no sentido de retomar, organizar, contextualizar, provocar, dar sentido aos entendimentos que estão sendo construídos. O diálogo mediador não deve abreviar o pensamento do estudante ou aceitar elaborações mais rápidas e simples, mas provocar a ampliação de seu pensar.

A subcategoria crenças e atitudes refere-se à compreensão e aceitação da deficiência intelectual e valorização da diversidade, bem como a influência de atitudes que interferem na prática inclusiva e no processo educativo. Refere-se, portanto, a percepção que o docente possui sobre o aluno com deficiência intelectual.

Os artigos que apresentam aspectos que se relacionam a esse tema destacam a importância do olhar docente para além dos aspectos orgânicos e déficits, superando concepções naturalizantes da deficiência e reconhecendo a diversidade e heterogeneidade dos alunos. Destacam, ainda, a importância de não cristalizar o olhar na dificuldade ou deficiência como um problema intrínseco do aluno, mas compreendendo-a também como fruto das interações sociais e pedagógicas, ou seja, ultrapassando os estereótipos delimitadores e abrindo-se para novas compreensões e configurações individuais e sociais (OLIVEIRA; MARTINS, 2011; TOLEDO; VITALIANO, 2012; ESTEVES; 
CRUZ; BERTELLI, 2013; ALBUQUERQUE; MORI; LACANALLO, 2009; PLETSCH; GLAT, 2012).

Silva e Oliveira (2010) destacam a importância de reconhecer a diversidade e heterogeneidade dos alunos, reconhecendo-os como participantes ativos e interativos do processo de aprendizagem para que se possam criar ambientes motivadores para o desenvolvimento. Gomes e Gonzales-Rey (2008) ressaltam a importância de se valorizar os aspectos subjetivos de cada sujeito considerando as trocas sociais. Nesse sentido, afirmam que o resgate aos alunos com necessidades especiais como "sujeitos" não mais formatados em estereótipos delimitadores é a base para a configuração de novos sentidos sociais e individuais, que alavanquem suas identidades, gerando novas configurações sociais e individuais, com ações e valores próprios.

A subcategoria formação engloba a formação inicial e continuada de professores e da gestão escolar para identificação, avaliação e práticas pedagógicas voltadas aos alunos com DI, bem como uma constante reflexão e questionamento das atitudes como educadores.

Muitos estudiosos apontam para a formação de professores como um dos temas fundamentais a ser trabalhado quando se pensa em inclusão. Com relação a esse tema relacionado à DI, destacam-se: a) a falta de programas de formação voltados para o conhecimento das características específicas das deficiências e da DI, acarretando insegurança e dificuldade de implementação de alternativas diferenciadas e flexíveis no trabalho pedagógico; b) a necessidade da formação estar articulada com a reflexão filosófica, rompendo com concepções errôneas e estáticas sobre a educação dos sujeitos com DI, o que se articula com a subcategoria anterior das crenças e atitudes; c) a importância da reformulação curricular e conceitual dos cursos de formação de professores articulando aspectos conceituais e concepções com conhecimentos teórico-práticos que fundamentem e deem suporte às mediações e ações pedagógicas. Ao se pensar formação e professores para inclusão é fundamental a clareza de que esse processo deve ser contínuo e que propostas que busquem articular diferentes áreas e promovam estudos cooperativos para busca de soluções aos desafios cotidianos é um caminho profícuo (LOPES; MARQUEZINE, 2012; FERREIRA; FERREIRA; OLIVEIRA, 2010; BEZERRA; ARAUJO, 2011a; OLIVEIRA; MARTINS, 2011; PLETSCH; GLAT, 2012). Outro aspecto identificado e que pode potencializar e permitir avanços importantes com relação à articulação das situações cotidianas com os conhecimentos teóricos é a articulação dos grupos de pesquisa das Universidades com as escolas, principalmente quando as pesquisa envolvem os professores como participantes ativos e reflexivos no processo (TOLEDO; VITALIANO, 2012). 
Cabe ainda ressaltar que não identificamos publicações que tragam contribuições significativas sobre essa questão nos anos de 2014 e 2015. Um movimento mais intenso de pensar e problematizar a formação docente parece ter acontecido logo após a implementação da Política Nacional de Educação Especial na Perspectiva da Educação Inclusiva (BRASIL, 2008). Identificamos muitas publicações em 2011 e 2012, apontando as lacunas e alguns caminhos, talvez na expectativa de acolhimento de políticas públicas que considerassem a necessidade da atenção e qualificação e discussão sobre a formação de professores. O aumento das matrículas de alunos com DI nas escolas comuns fez emergir novas problemáticas desvelando as fragilidades do processo educacional e destinando muitas investigações ao entendimento e acompanhamento desses processos.

\section{CONSIDERAÇÕES FINAIS}

A realização desse estudo permitiu identificar aspectos facilitadores para a inclusão de estudantes com deficiência intelectual em escolas comuns a partir da análise de artigos publicados de 2008 a 2015. Os artigos analisados apresentaram contribuições para as cinco categorias de análise definidas a priori, embora a discussão tenha se concentrado nas categorias escola e professores. Evidenciamos que a produção científica têm apontado possibilidades, práticas e indicadores que podem favorecer o processo de inclusão do estudante com deficiência intelectual, ao contrário de estudos anteriores em que grande parte dos achados se concentrava nos aspectos dificultadores das práticas educacionais na perspectiva da inclusão.

A partir das análises e reflexões realizadas é possível destacar que a prática educacional inclusiva implica no entendimento dessa concepção para além da compreensão das características da deficiência intelectual e convoca a acolher a diversidade das experiências de aprender. Além disso, o sucesso das práticas educacionais inclusivas e do processo de escolarização do estudante com deficiência intelectual implica no envolvimento e articulação de diferentes agentes desse processo (professores da escola comum, professores do AEE, gestores das escolas, profissionais especialistas das diferentes áreas, família e estudantes). Essa articulação se evidencia tanto como um aspecto facilitador como também um grande desafio considerando os contextos sociais e educacionais de nosso país.

A categoria professores evidenciou a necessidade de o docente construir sua prática pedagógica articulada em princípios da interação e cooperação entre os estudantes, considerando as 
experiências e potenciais destes, além de articular suas intervenções com os princípios da mediação visando apoiar a estruturação do pensamento do estudante com DI.

Nas categorias não discutidas neste estudo (governo, família, colegas) identificamos menor número de aspectos facilitadores e pouca relação direta com a deficiência intelectual. A categoria governo apresentou alguns aspectos facilitadores concentrados mais em investimentos e na necessidade de clareza, aprofundamento e manutenção de programas destinados à promoção da educação na perspectiva da inclusão. Considera-se relevante que futuros estudos possam aprofundar a compreensão relativa aos processos de interação entre família e escola e entre colegas com e sem deficiência.

\section{REFERÊNCIA}

ALBUQUERQUE, R. A.; MORI, N. N. R.; LACANALLO, L. F. Salas de recursos e o uso de jogos para o ensino de conceitos matemáticos. Revista Educação Especial. Santa Maria, v. 22, n. 34, p. 155-164, 2009.

ANUNCIACAO, L.M.R.L.; COSTA, M.P.R.; DENARI, F.E. Educação Infantil e Práticas Pedagógicas para o aluno com Síndrome de Down: o enfoque no Desenvolvimento Motor. Revista Brasileira de Educação Especial, Marília , v. 21, n. 2, p. 229-244, 2015

ARAÚJO, S.L.S.; ALMEIDA, M.A. Contribuições da consultoria colaborativa para a inclusão de pessoas com deficiência intelectual. Revista Educação Especial. Santa Maria, v. 27, n. 49, p. 341-352, 2014.

BARDIN, L. Análise de conteúdo. São Paulo: Edições 70, 2011.

BELO, C. et al. Deficiência intelectual: metodologia e conceptualização. Revista Diversidades. Região Autonoma de Madeira, n. 22, ano 6, p. 4-9, 2008.

BEYER, H. O. Inclusão e avaliação na escola: de alunos com necessidades educacionais especiais. Porto Alegre: Mediação, 2010.

BEZERRA, G. F.; ARAUJO, D.A.C. De volta à teoria da curvatura da vara: a deficiência intelectual na escola inclusiva. Educação em Revista, Belo Horizonte, v. 27, n.2, p. 277-302, 2011a.

BEZERRA, G. F.; ARAUJO, D.A.C. Atividades linguísticas e cognitivas para alunos com deficiência intelectual: proposta metodológica na inclusão escolar. Revista Educação Especial. Santa Maria, v. 24, n. 40, p. 233-244, 2011 b.

BISOL, C.A.; STANGHERLIN, R.G.; VALENTINI, C.B. Educação inclusiva: estudo de estado da arte das publicações científicas brasileiras em Educação e Psicologia. Cadernos de Educação. Pelotas, n. 44, p. 240-264, 2013.

BRASIL. MEC/SEE. Política nacional de educação especial na perspectiva da educação inclusiva. Brasília, SEESP, 2008.

BRAUN, P.; NUNES, L.R.O. A Formação de Conceitos em Alunos com Deficiência Intelectual: o Caso de Ian. Revista Brasileira de Educação Especial. Marília, v. 21, n. 1, p. 75-92, 2015.

CAMPOS, M.L.B. Adaptação psicossocial parental à deficiência mental. 2002. 213 f. Dissertação (Mestrado em Psiquiatria e Saúde Mental) - Faculdade de Medicina da Universidade do Porto, Porto, 2002.

CARLINO, E. P. A cidadania evidenciada na diferença. Revista Educação Especial. Santa Maria, v. 23, n. 38, p. 409422, 2010.

CECHIN, M.B.C.; COSTA, A.C.; DORNELES, B. V. Ensino de fatos aritméticos para escolares com deficiência intelectual. Revista Brasileira de Educação Especial, vol.19, n.1, p.79-92, mar. 2013.

CHARLOT, B. Relação com o saber, formação de professores e Globalização. Questões para a educação hoje. Porto Alegre: Artmed, 2005. 
CRUZ, G. C.; LEMISHKA, I. Ambientes inclusivo e exclusivo no processo ensino-aprendizagem de pessoas com deficiência mental em aulas de educação física. Revista Educação Especial. Santa Maria, v. 23, n. 37, p. 315-326, 2010 .

CUNHA, R.; ROSSATO, M. A singularidade dos estudantes com deficiência intelectual frente ao modelo homogeneizado da escola: reflexões sobre o processo de inclusão. Revista Educação Especial, v. 28 , n. 53 , 2015.

DALPRETTO, B.M.L.; SANTOS, B.C.C. Um contexto em transformação político-pedagógico: a articulação entre uma escola regular e um centro de atendimento especializado. Revista Educação Especial. Santa Maria, v. 26, n. 47, p. 727$742,2013$.

DIAS, S.S; OLIVEIRA, M.C.S.L. Deficiência intelectual na perspectiva histórico-cultural: contribuições ao estudo do desenvolvimento adulto. Revista Brasileira de Educação Especial, v. 19, n. 2, p. 169-182, 2013.

ECHEITA, G.; AINSCOW, M. La Educación Inclusiva como derecho. Marco de referencia y pautas de acción para el desarrollo de una revolución pendiente. II CONGRESSO IBEROAMERICANO DE SÍNDROME DE DOWN Palestra. Granada, 2010.

ESTEVES, L. M.; CRUZ, E. C.; BERTELLI, R. Níveis de envolvimento de uma criança com Síndrome de Down em contextos de inclusão e educação especial. Revista Educação Especial, Santa Maria, v. 26, n. 45, p. 31-44, 2013.

FANTACINI, R. A. F.; DIAS, T. R. da S. Professores do Atendimento Educacional Especializado e a Organização do Ensino para o Aluno com Deficiência Intelectual. Revista Brasileira de Educação Especial. Marília, v. 21, n. 1, p. $57-$ $74,2015$.

FERRAZ, C.R.A.; ARAÚJO, M.V.; CARREIRO, L.R.R. Inclusão de crianças com Síndrome de Down e Paralisia Cerebral no ensino fundamental I: comparação dos relatos de mães e professores. Revista Brasileira Educação Especial. Marília, v. 16, n. 3, p. 397-414, 2010.

FERREIRA, D.R.S.A.; FERREIRA, W.A.; OLIVEIRA, M.S. Pensamento e linguagem em crianças com síndrome de Down: um estudo de caso da concepção das professoras. Ciências \& Cognição. Rio de Janeiro, v. 15, n. 2, p. 216-227, 2010 .

GARGHETTI, F.C.; NUERNBERG; A.H.; MEDEIROS, J.G. Um estudo observacional sobre as interações de crianças/adolescentes com deficiência intelectual no ensino regular. Educação: Revista do Centro de Educação UFSM, v. 40, n. 2, p. 451-464, 2015.

GLAT, R.; PLETSCH, M.D. Orientação familiar como estratégia facilitadora do desenvolvimento e inclusão de pessoas com necessidades especiais. Revista Educação Especial, n. 24, 2004.

GOMES, C.; GONZALES-REY, F.L. Psicologia e inclusão: aspectos subjetivos de um aluno portador de deficiência mental. Revista Brasileira Educação Especial. Marília, v. 14, n. 1, p. 53-62, 2008.

HEIN, J.M. et al. Avaliação da eficácia do software "Alfabetização Fônica" para alunos com deficiência mental. Revista Brasileira Educação Especial, Marília, v. 16, n. 1, p. 65-82, 2010.

LIBÂNEO, J. C. A didática e aprendizagem do pensar e do aprender: a Teoria Histórico-cultural da atividade e a contribuição de Vasili Davydov. Revista Brasileira e Educação. Rio de Janeiro, n. 27, 2004.

LIMA, S.R.; MENDES, E.G. Escolarização da pessoa com deficiência intelectual: terminalidade específica e expectativas familiares. Revista Brasileira Educação Especial. Marília, v. 17, n. 2, p. 195-208, 2011.

LOPES, E.; MARQUEZINE, M.C. Sala de Recursos no Processo de Inclusão do Aluno com Deficiência Intelectual na Percepção dos Professores. Revista Brasileira Educação Especial. Marília, v. 18, n. 3, p. 487-506, 2012.

LUIZ, F.M.R.; NASCIMENTO, L.C. Inclusão escola com crianças com Síndrome de Down: experiências contadas pelas famílias. Revista Brasileira Educação Especial. Marília, v. 18, n. 1, p. 127-140, 2012.

LUIZ, F.M.R. et al. Inclusão de crianças com Síndrome de Down. Psicologia em Estudo, v. 17, p. 649-658, 2012.

MEDRADO, G.; GOMES, V.M.; NUNES SOBRINHO, F.P. Atributos teórico-metodológicos da revisão sistemática das pesquisas empíricas em educação especial: evidências científicas na tomada de decisão sobre as melhores práticas inclusivas. In: NUNES, L.R.O.P. (Org.). Novas trilhas no modo de fazer pesquisa em educação especial. São Carlos: Marquezine \& Manzini, 2014, p. 105-126.

OLIVEIRA, E.S.; MARTINS, L.A.R. Currículo e diversidade: os desafios da inclusão escolar de alunos com deficiência intelectual. Linhas Críticas. Brasília, DF, v. 17, n. 33, p. 309-325, 2011. 
PEDRO, K.M.; CHACON, M.C.M. Softwares educativos para alunos com Deficiência Intelectual: estratégias utilizadas. Revista Brasileira Educação Especial. Marília, vol. 19, n. 2, p. 195-210, 2013.

PLETSCH, M.D. Repensando a inclusão escolar: diretrizes políticas, práticas curriculares e deficiência intelectual. 2. ed. rev. e ampl. Rio de Janeiro: NAU, 2014.

; GLAT, R. A escolarização de alunos com deficiência intelectual: uma análise da aplicação do Plano de Desenvolvimento Educacional Individualizado. Linhas Críticas. Brasília, DF, v. 18, n. 35, p. 193-208, 2012.

RODRIGUES, O.M.P.R.; SANTOS, L.H.Z.; CARLINO, F.C. Intervenção em habilidades sociais com uma criança com síndrome de down. Revista Educação Especial. Santa Maria, v. 27, n. 48, p. 95-110, 2014.

RODRIGUES, V.; CAMPOS, J.A.P.P.; ALMEIDA, M.A. Uso do PECS associado ao video modeling na criança com Síndrome de Down. Revista Brasileira de Educação Especial, Marília, v. 21, n. 4, p. 379-392, 2015.

SACRISTAN, J.G. O currículo: uma reflexão sobre a prática. 3. ed. Porto Alegre: Artmed, 2000.

SANTOS, D.C.O. Potenciais dificuldades e facilidades na educação de alunos com deficiência intelectual. Educação e Pesquisa. São Paulo, v. 38, n. 4, p. 935-948, 2012.

SANTOS, T.; MENDES, E.G. O efeito da tutoria de colegas sobre o desempenho de alunos com deficiência em classes inclusivas. Revista Educação Especial. Santa Maria, n. 32, p. 211-224, 2008.

SANTOS, T.C.C.; MARTINS, L.A.R. Práticas de Professores Frente ao Aluno com Deficiência Intelectual em Classe Regular. Revista Brasileira de Educação Especial. Marília, v. 21, n. 3, p. 395-408, 2015.

SILVA, J; BELO, V.S.; DRUMOND, A.C. Análise dos processos de inclusão, desenvolvimento e aprendizagem de uma criança com Síndrome de Down matriculada na escola comum. Revista Educação Especial. Santa Maria, v. 24, n. 40, p. 245-258, 2011.

SILVA, M.C.L., OLIVEIRA, M.S. Concepção dos professores sobre a apropriação de conhecimentos Matemáticos por crianças com síndrome de Down. Revista Educação Especial, Santa Maria, v. 23, n. 37, p. 257-272, 2010.

SMEHA, L.N.; OLIVEIRA, V.L.P. Inclusão escolar: a perspectiva das mães de alunos com Síndrome de Down. Revista Educação Especial. Santa Maria, v. 27, n. 49, p. 403-416, 2014.

STELMACHUK, A.C.L.; MAZZOTTA, M.J.S. Atuação de profissionais da educação na inclusão escolar do aluno com deficiência intelectual. Revista Educação Especial. Santa Maria, v. 25, n. 43, p. 185-202, 2012.

; HAYASHI, M.C.P. Análise bibliométrica sobre avaliação de pessoas com deficiência intelectual para ingresso em serviços de educação especial. REICE: Revista Electrónica Iberoamericana sobre Calidad, Eficacia y Cambio en Educación, v. 13 n. 2, p. 27-49, 2015.

TEIXEIRA, F.C.; KUBO, O.M. Característica das interações entre alunos com Síndrome de Down e seus colegas de turma no sistema regular de ensino. Revista Brasileira Educação Especial. Marília, v. 14, n. 1, p. 75-92, 2008.

TOLEDO, E.H.; VITALIANO, C.R. Formação de professores por meio de pesquisa colaborativa com vistas à inclusão de alunos com deficiência intelectual. Revista Brasileira Educação Especial. Marília, v. 18, n. 2, p. 319-336, 2012.

VELTRONE, A.A.; MENDES, E.G. Inclusão e fracasso escolar: o que pensam os alunos com deficiência mental? Revista Educação Especial. Santa Maria, v. 22, n. 33, p. 59-72, 2009.

; MENDES, E. G. Descrição das propostas do Ministério da Educação na avaliação da deficiência intelectual. Paidéia. Ribeirão Preto, v. 21, n. 50, p. 413-421, 2011a.

; MENDES, E.G. Percepções dos alunos com deficiência intelectual sobre sua matricula na classe especial e classe comum. Revista Eletrônica de Educação. São Carlos, v. 5, n. 2, p. 59-81, 2011 b.

VELTRONE, A.A.; MENDES, E.G. Impacto da mudança de nomenclatura de deficiência mental para deficiência intelectual. Revista Educação em Perspectiva, v. 3, n. 2, 2013.

VIGOTSKI, L.S. A defectologia e o estudo do desenvolvimento e da educação da criança anormal. Educação e Pesquisa. São Paulo, v. 37, n. 4, p. 863-869, 2011. 


\section{RESUMO}

O presente trabalho tem como objetivo identificar aspectos facilitadores para a inclusão de estudantes com deficiência intelectual em escolas comuns, a partir de revisão sistemática de literatura. 0 corpus de análise foi composto por 44 artigos publicados em periódicos científicos nacionais de 2008 a 2015, localizados através dos descritores: deficiência mental, deficiência intelectual, Síndrome de Down e inclusão escolar. Análise de conteúdo de Bardin permitiu identificar aspectos facilitadores específicos (planejamento, adequação curricular, formação de professores, estrutura, investimentos, etc.), além de aspectos relacionados à aceitação da diversidade, crenças e atitudes como caminhos que podem viabilizar mudanças no cotidiano das escolas.

Palavras-chave: Educação inclusiva; deficiência intelectual; aspectos facilitadores.

\section{INCLUSION OF STUDENTS WITH INTELLECTUAL DISABILITIES: A SYSTEMATIC REVIEW OF LITERATURE}

\section{ABSTRACT}

This study aims to identify facilitating aspects for the inclusion of students with intellectual disabilities in mainstream schools, based on a systematic review of literature. The corpus of analysis consisted of 44 articles published in national scientific journals from 2008 to 2015, located through the search terms: intellectual disabilities, mental retardation, Down syndrome and school inclusion. Bardin content analysis allowed the identification of specific facilitating aspects (planning, curriculum adaptation, teacher training, structure, investment, etc.), as well as aspects related to the acceptance of diversity, beliefs and attitudes that can enable changes in the daily routine of schools.

Keywords: Inclusive education; intellectual disability; facilitating aspects.

Submetido abril 2016

Aprovado jun. 2016 